\title{
A RANDOMIZED TRIAL ON EFFECTIVENESS OF HOME BASED CARE COMPARED TO CONVENTIONAL CARE FOR ANTENATAL WOMEN WITH GESTATIONAL HYPERTENSION
}

\author{
Latha S1, Srikanth S2, Subasri B33, Barathalakshmi J, Nidhi Bansal5, Sathiyabama S6, Susiganeshkumar E7 \\ 1 Professor, Department of Paediatrics Nursing, Indirani College of Nursing, SVMCH \& RC Campus, Puducherry. \\ 2Professor, Department of Community Medicine, Sri Venkateshwaraa Medical College Hospital \& Research Centre (SVMCH \& RC). \\ ${ }^{3}$ Consultant, RUWSEC, Kancheepuram. \\ ${ }^{4}$ Assistant Professor, Department of Community Medicine, SVMCH \& RC, Puducherry. \\ ${ }^{5}$ Assistant Professor, Department of Obstetrics and Gynaecology, SVMCH \& RC, Puducherry. \\ ${ }^{6}$ Associate Professor, Department of Obstetrics and Gynaecology Nursing, Indirani College of Nursing, Puducherry. \\ ${ }^{7}$ Assistant Professor, Department of Community Medicine, SVMCH \& RC, Puducherry.
}

\section{ABSTRACT}

\section{BACKGROUND}

Approximately $70 \%$ of hypertensive disorders in pregnancy are constituted by gestational hypertension, in which $15-25 \%$ of cases progress to pre-eclampsia. This study was undertaken to assess whether home based care for gestational hypertension would reduce pre-eclampsia and improve maternal and fetal outcomes compared to conventional care.

\section{MATERIALS AND METHODS}

A randomized controlled community based study was carried out during 2014-2015 in the service areas of a Medical College at Puducherry. One hundred and three antenatal mothers with gestational hypertension (systolic blood pressure $\geq 140 \mathrm{mmHg}$ and/or diastolic blood pressure $\geq 90 \mathrm{mmHg}$ ) were randomly enrolled into home care group $(\mathrm{n}=52)$ and conventional care group ( $\mathrm{n}=51$ ). The home care group mothers were monitored at home by three auxiliary nurse midwives. Blood pressure, weight, pedal edema, urine albumin, fetal movements, fetal heart rate and warning signs of eclampsia were assessed periodically. Both groups received usual antenatal care at hospital. Maternal and fetal outcomes at delivery were analyzed using SPSS 17.

\section{RESULTS}

The mean age of the mothers was $25.0 \pm 3.9$ yrs. A significant reduction $(\mathrm{p}<0.05)$ in mean diastolic blood pressure was observed in both the groups. A reduction in mean systolic pressure was observed in home care mothers. Twenty mothers (19\%) progressed to pre-eclampsia-17\% in home care and $22 \%$ in conventional care group. At delivery, $46 \%$ mothers in home care and $37 \%$ of mothers in conventional care had normal blood pressure. Significant weight gain $(p<0.05)$ was observed in home care mothers. Prolongation of pregnancy to term was $89 \%$ in home care and $84 \%$ in conventional care group. No significant neonatal outcomes were observed between the two groups. However, low birth weight babies were more in conventional care group.

\section{CONCLUSION}

Home based care for gestational hypertension could be an acceptable strategy. Large scale studies are needed for more scientific evidence.

\section{KEYWORDS}

Gestational Hypertension, Home Care, Pre-eclampsia, Pregnancy-Induced Hypertension.

HOW TO CITE THIS ARTICLE: Latha S, Srikanth S, Subasri B, Barathalakshmi J, Nidhi Bansal, Sathiyabama S, Susiganeshkumar E. "A Randomized Trial on Effectiveness of Home Based Care Compared to Conventional Care for Antenatal Women with Gestational Hypertension." Journal of Evolution of Medical and Dental Sciences 2015; Vol. 4, Issue 96, November 30; Page: 16175-16180, DOI: $10.14260 /$ jemds/2015/2375

\section{INTRODUCTION}

In India while maternal deaths due to haemorrhage and infections are decreasing, deaths due to hypertension are increasing.1,2,3 Gestational hypertension constitutes about $70 \%$ of hypertensive disorders in pregnancy. 4,5 It occurs after 20 weeks of gestation, characterised by a systolic blood pressure (SBP) $\geq 140 \mathrm{mmHg}$ and/or diastolic blood pressure (DBP) $\geq 90 \mathrm{mmHg}$ without proteinuria.

Financial or Other, Competing Interest: None.

Submission 13-11-2015, Peer Review 14-11-2015,

Acceptance 23-11-2015, Published 28-11-2015.

Corresponding Author:

Dr. Srikanth $S$,

Professor,

Department of Community Medicine,

Sri Venkateshwaraa Medical College Hospital \&

Research Centre,

Puducherry - 605102.

E-mail: srikanthlatha2003@yahoo.co.in

DOI:10.14260/jemds/2015/2375
Although maternal risks with gestational hypertension are generally less compared to pre-eclampsia, approximately $15-25 \%$ of them progress to pre-eclampsia leading to severe obstetric complications including death. Hence, it is mandatory to monitor and treat each case of gestational hypertension as emerging pre-eclampsia.6,7 One of the important objective of antenatal care is to detect such high risk women and give them special care. Unfortunately, many women receive inadequate prenatal care because of problems of accessibility, financial constraints as well as personal and social reasons. ${ }^{3,8}$

In the conventional management of gestational hypertension, the women are advised about warning signs of eclampsia, adequate bed rest at home, blood pressure monitoring at a locally available health facility and reporting to the hospital for timely delivery. 9,10 However, there are no proper guidelines or uniformity in referral thresholds and assessment procedures of these women at community level. 11,12

Home based antenatal care primarily by a trained midwife along with institution based care by obstetrician has 
been recognized as a model globally. Hence, delivering such type of care to antenatal women with gestational hypertension could reduce the barriers and potentially improve pregnancy outcomes..$^{13}$ Limited reports are available from observational studies on home care plan for women with mild pre-eclampsia. ${ }^{14}$ No randomized trials have been reported on the impact of home based care of gestational hypertension compared to that of conventional care. In this context, the investigators explored the effectiveness of a home care approach for women with gestational hypertension with the existing routine care service in improving the maternal and neonatal outcomes at delivery.

\section{Research Question}

Is a home based care program for antenatal women with gestational hypertension effective in reducing maternal and neonatal outcomes in terms of morbidity and mortality as compared to conventional antenatal care?

\section{MATERIALS AND METHODS}

A community based interventional study was conducted between March 2014 and February 2015 in the service areas of a Medical College in Puducherry, after obtaining permission from the Institutional Ethics Committee. Permission to screen and recruit antenatal women for the study was obtained from the Director of Medical Services, Govt. of Puducherry, Medical Superintendent of Government Maternity Hospital (RGGMH) and Director of Indira Gandhi Government Medical College respectively.

The sample size was calculated using OPEN EPI software. Taking $\mathrm{P}_{1}$ as the proportion of antenatal women with hypertension who became normotensive by home based nursing care (56\%), as reported in an earlier study. ${ }^{15}$ and with an assumption that conventional care $\left(\mathrm{P}_{2}\right)$ outcome would be $50 \%$ less than home based nursing care, the sample size was calculated to be 48 in each group with $\mathrm{Z} \alpha$ at 0.05 and power of study as $80 \%$. It was decided to recruit 50 mothers in each group.

Three Auxiliary Nurse Midwives (ANM) were recruited for the study. They were trained on antenatal care aspects pertaining to gestational hypertension. Training content was adopted from "Skilled Birth Attendant Module for Antenatal Care $^{1}$ (SBA)" of Department of Family Welfare, Ministry of Health and Family Welfare, Govt. of India. Training was imparted by Community Medicine Physicians, an obstetrician and two nurses specialized in Maternal and Child Health Nursing. Pretest and Post-test were conducted to assess the change in knowledge and practice of the ANMs, before and after the training. Periodic sensitization was conducted for these ANMs during the study period.

Antenatal mothers attending the Obstetric Outpatient Department were screened for gestational hypertension by the ANMs. Eligible women (Gestational age between 20 wks. and 34 wks.; no other high risk factors) were randomly enrolled either into home care group (Intervention) or conventional care (Control) group after written consent. The home care mothers were monitored at home on alternate days by the ANMs. Blood pressure, weight, pedal edema, urine albumin, fetal movements, fetal heart rate and warning signs of eclampsia were assessed and documented. Advice on diet, adequate rest and medication compliance were given periodically.

The mothers were informed to call the ANM over the phone in case of any emergencies. Any woman with clinical deterioration such as proteinuria, Systolic $\mathrm{BP} \geq 160 \mathrm{mmHg}$ and/or diastolic $\geq 110 \mathrm{mmHg}$, was referred to the hospital immediately. Regular antenatal check up in the hospitals was continued for both groups. All clinical decisions regarding management and delivery were at the discretion of the obstetricians.

Delivery details of the mother and baby were documented from the hospital records. Maternal outcomes in terms of blood pressure changes, weight gain, morbidity and mortality were assessed. Fetal outcomes in terms of birth weight, gestational age at delivery, morbidity and mortality were assessed. Data entry and analysis were done with SPSS software version 17.

Flow Chart: Recruitment of Antenatal women with Gestational Hypertension.

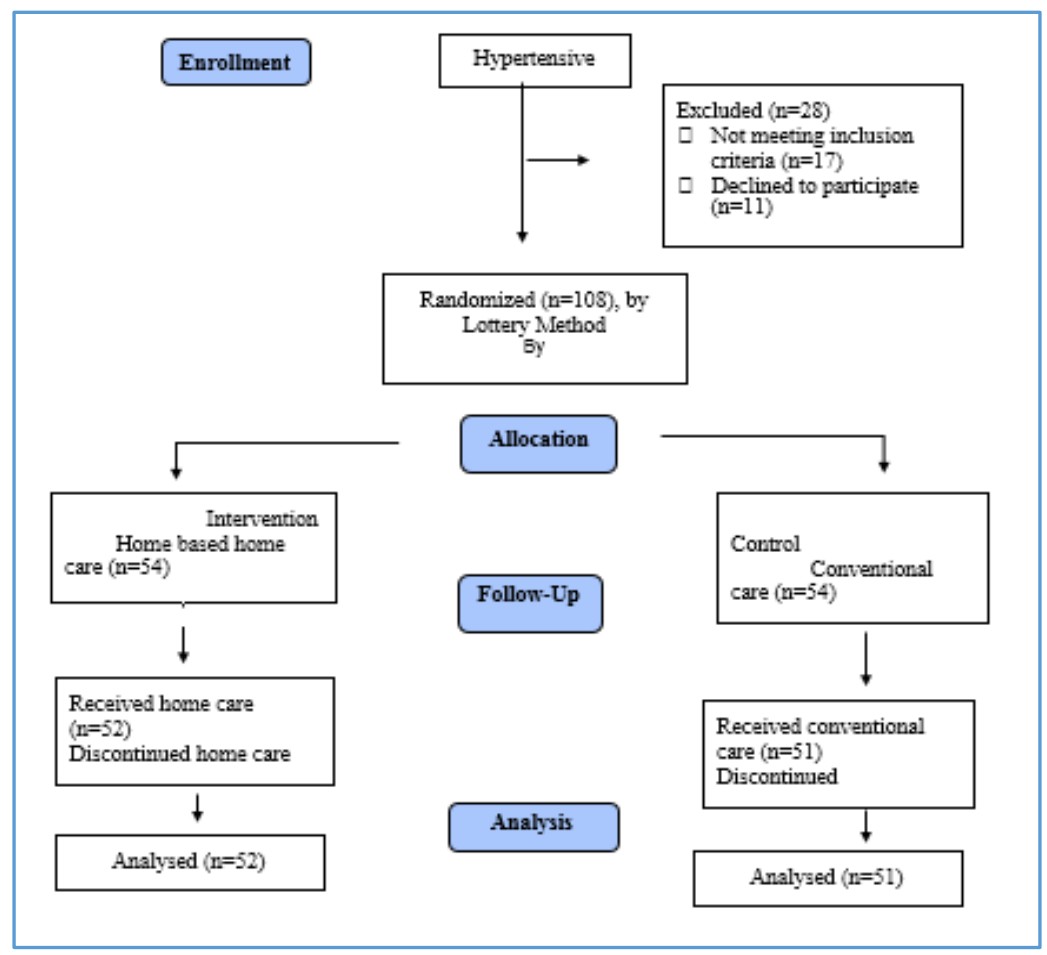




\section{MATERNAL OUTCOMES}

Women on home care had an average weight gain of five kilograms $(\mathrm{p}<0.05)$, decrease in mean systolic blood pressure and a significant decrease in mean diastolic blood pressure $(p<0.01)$. In the conventional care group, decrease in weight, an increase in mean systolic blood pressure and a significant decrease in mean diastolic blood pressure $(\mathrm{p}<0.01)$ was noted (Table 3).

Overall, 58\% women continued to have hypertension till delivery. Blood pressure became normotensive (SBP $<140 \mathrm{mmHg}$ and DBP $<90 \mathrm{mmHg}$ ) among $46 \%$ of mothers in home care group and $37 \%$ in conventional care group at delivery. There were no eclampsia cases or mortality in both the groups. Eleven women (22\%) in conventional care group and nine women $(17 \%)$ in home care had signs of preeclampsia. However, it was not statistically significant $(\mathrm{p}=0.617)$. More women $(31 \%)$ in conventional care group were on antihypertensive medications compared to home care group (25\%) (Table 4).

\section{NEONATAL MORBIDITY AND MORTALITY}

All the deliveries were institutional. Overall, $10 \%$ of deliveries were preterm. Preterm delivery was more in conventional care group (12\%) than home care group (8\%). There was no significant difference $(p>0.05)$ in the mean gestational age at delivery between the groups. Low birth weight babies $(<2.5 \mathrm{~kg})$ were more in conventional care group than in home care group. There was no significant difference $(p>0.05)$ in the mean birth weight between the groups.

There was no significant difference $(p>0.05)$ in the APGAR status between the groups. There was one stillbirth in both the groups. Neonatal morbidity was documented in 14 babies $(27 \%)$ in home care group and 18 babies (35\%) in the conventional care group. Birth asphyxia was more in conventional care group than home care group. There was no significant difference $(\chi 20.728, p>0.05)$ in overall morbidity status of neonates between the groups (Table 5).

\section{DISCUSSION}

In our study, about $2.3 \%$ of mothers screened had gestational hypertension. Pregnancy Induced Hypertension (PIH) reported in other Indian studies ranged between 3\%-6\%.16,17 Advanced maternal age is known to be a risk for PIH. The mean age of mothers in our study was 25 years. Forty percent of mothers were in second trimester at recruitment and 58\% were nulliparous. Similar findings have been reported in studies from India.16,17,18 and abroad.19,20 Majority of the participants were housewives. This was consistent to the observation by Borade et al. ${ }^{2}$ Traditionally, these women take little bed rest at home and do not refrain from physical work irrespective of their pregnancy status.

An average increase of $5 \mathrm{~kg}$ (From recruitment period) was observed in the home care group. An average weight gain of $6.5 \mathrm{~kg}$ during the entire pregnancy period is usually seen in Indian mothers. ${ }^{3}$ As per literature evidence, nearly one fifth of women with gestational hypertension progress to preeclampsia. ${ }^{7}$ In this study, $19 \%$ mothers had developed signs of pre-eclampsia. Preeclampsia was more (65\%) among those who had hypertension at gestation $<30$ weeks. Arias F et al. ${ }^{10}$ had documented a similar observation.

Even though a statistical significance was not achieved, incidence of pre-eclampsia was less in home care group compared to conventional care mothers. Nineteen $(37 \%)$ mothers in conventional care group became normotensive during the study period. Hence, we expected 38 mothers (Ref: sample size calculation). ${ }^{15}$ in the intervention group to become normotensive as a consequence of home based nursing care. Even though this was not accomplished, nearly two-third mothers (24/38) became normotensive in the home care group.

In our study, we observed that prolongation of gestation to term was slightly more in home care group (89\%) than conventional care group (84\%). Normal deliveries were more in home care group. About $13 \%$ of total deliveries were of low birth weight, more among the conventional group (15\%) than home care group (10\%). Neonatal morbidity was less in home care mothers compared to conventional care mothers. However, statistical significance could not be established in these observations. Pre-eclamspia is associated with early GA at delivery and low birth weight. ${ }^{21}$ about $30 \%$ of deliveries among pre-eclampsia mothers were of low birth weight and preterm in the present study. Also both the mothers who had stillbirth had pre-eclampsia.

Worldwide, midwifery model of care and delivery has brought forth acceptance and recognition in reducing maternal morbidity and mortality. Studies from Western Countries have reported the beneficial effects of prenatal home care for high risk pregnancies. ${ }^{22,23}$ A PIH related maternal death audit on 622 deaths during 2005-2007 in South Africa ${ }^{24}$ had reported nonattendance for antenatal care $(19 \%)$ and delay in seeking help (19\%) as patient related causes. Such factors could be avoided in prenatal home care. The safety and acceptability of a community based nursing program for pre-eclampsia was studied among 321 mothers in Winnepeg. ${ }^{15}$ While $56 \%$ of study subjects showed better maternal outcomes in terms of blood pressure, rest (44\%) got admitted due to worsening of pre-eclampsia. The program had received good support from the mothers. Regular monitoring and compliance of mothers was quoted as the success of the program.

In the Reproductive and Child Health Program (RCH) of India, the auxiliary nurse midwives provide most of vital antenatal services in Subcentres and Primary Health Centres. ${ }^{25}$ Increasing their skills to monitor pregnancyinduced hypertension would decrease potential maternal and fetal complications. A protocol based nursing care at home could supplement the routine hospital care of women with gestational hypertension. It has advantages such as reducing transportation problems, long waits in the Outpatient Departments and interruption of bed rest.22

In our health system, for an ANM covering 5000 population in a Subcentre Area, assuming birth rate of 21/1000 population, 115 pregnant mothers are expected at any time in a year. ${ }^{3}$ There would be $10 \mathrm{PIH}$ mothers (Assuming 10\% of all pregnancies). Even if a woman without risk is attending antenatal clinic regularly, she must be paid at least one home visit. ${ }^{3}$ Hence women with gestational hypertension could be paid additional home visits. Such home visits will win the confidence of the antenatal mother and will favour better maternal and fetal outcomes.

The median number of visits by the ANMs in the present study was 24 . Other studies on home visits of high risk mothers have reported an average of 7-25.1 visits. ${ }^{23,26}$ Twenty eight mothers were referred to obstetrician during the study period. In a trial in Huddersfield, 38 women with gestational hypertension were visited two to three times weekly by community midwives.

It was observed that compared to routine care, admissions were less in intervention group and inpatient days were less during the study period of six months. Supervision of PIH women at home had added 5\% in the workload of midwives. In addition, good rapport was reported between the mother and community midwife, which was a great benefit after delivery. ${ }^{27}$

Documentation of data in our study was found to be extensive. This could be an additional workload for an ANM considering her other responsibilities in the community. 
However, providing additional care to these women would not be a concern if other grass root level workers like ASHA could monitor the urine albumin and fetal movement status of the mothers and provide the information to the ANM during home visits.

The limitations in this study were that the small sample size restricts the generalizability of the findings of our study and cost comparison analysis of home based care with conventional care was not done. To conclude, home based care program for gestational hypertension would be a feasible and acceptable strategy to the community and obstetricians. Similar studies could be evaluated on a large scale for more scientific evidence.

\section{ACKNOWLEDGEMENT}

The authors acknowledge the support rendered by

- Maternal Health Task Force Team at Harvard T.H.Chan School of Public Health, through Grant from Bill \& Mellinda Gates Foundation.

- MHYP Mentoring Program Team under Dr Prem K Mony, St. John's Medical College \& Research Institute, Bangalore.

\section{The authors express their sincere thanks to the following} persons:

- Dr. K.V. Raman, Director of Medical Services, Government of Puducherry.

- Dr. Jothi Boblee James, Medical Superintendent of Rajiv Gandhi Government Maternity Hospital, Puducherry.

- Dr. Jayakumar P, Former Director \& Dr Himabindu Professor OBG, Indira Gandhi Medical College \& Research Institute, Puducherry.

\section{REFERENCES}

1. Guidelines for antenatal care and skilled attendance at birth by ANMs and LHVs. Maternal Health Division, Dept. of Family Welfare, Ministry of Health \& Family Welfare, Govt. of India; 2005.

2. Borade PV, Haralkar SJ, Wadagale AV. Hypertensive disorders of pregnancy: An ongoing holocaust. Natl J Community Med 2014;5(1):61-65.

3. Park K. Park's text book of preventive \& social medicine. 22nd ed. Jabalpur: M/s Banarsidas Bhanot; 2013.

4. Coppage K, Sibai B. Preeclampsia and eclampsia. Glob.libr.women's med., (ISSN:17562228)2008;DOI10.3843/GLOWM.10158.Available from http://www.glown.com/section.../Preeclampsia\%20an d\%20Eclampsia/item/158[cited20130ct20].

5. Trivedi SS, Manju Puri. Management of high risk pregnancy. A practical approach. $1^{\text {st }}$ ed. New Delhi: Jaypee Brothers Medical Publishers (P) Ltd.; 2010.

6. Hutcheon JA, Lisonkova S, Joseph KS. Epidemiology of pre-eclampsia and the other hypertensive disorders of pregnancy. Best Practice \& Research Clinical Obstetrics and Gyneacology 2011;25:391-403.

7. Saudan P, Brown MA, Buddle ML, Jones M. Does gestational hypertension become preeclampsia? BJOG 1998;105(11):1177-84.

8. Ganesh KS, Unnikrishnan B, Nagaraj K, Jayaram S. Determinants of pre-eclampsia. A case control study in a district hospital in South India. Indian J Community Med 2010;35(4):502-505.

9. Gopalan S, Jain V. Mudaliar and Menon's Clinical obstetrics. Hypertensive disorders of pregnancy $10^{\text {th }} \mathrm{ed}$. Hyderabad: Universities Press (India) Ltd.;2005.

10. Arias F, Daftary SN, Bhide GA. Practical guide to high risk pregnancy and delivery. A South Asian perspective. Hypertensive disorders in pregnancy. $3^{\text {rd }}$ ed. New Delhi: Elsevier; 2008.
11. National Institute for Health and Clinical Excellence. Hypertension in pregnancy. The management of hypertensive disorders during pregnancy: NICE clinical guideline $107 . \quad$ Available from guidance.nice.org.uk/cg107[cited 2013 Oct 20].

12. Milne F, Redman C, Walker J, Baker P, Bradley J, Cooper $\mathrm{C}$ et al. The preeclampsia community guideline (PRECOG): How to screen for and detect onset of preeclampsia in the community. Brit Med J 2005;330:576.

13. World Health Organization. Maternal health. More skilled midwives needed to save women's and newborn's lives. Available from http:// www.who.int /mediacentre

/news/releases/2011/midwifery_report_20110620 /en/index.html [cited 2014 April 7].

14. Magee LA, Helewa M, Moutquine J, Dadelszen P. Diagnosis, evaluation, and management of the hypertensive disorders of pregnancy. J Obstet Gynaecol Can 2008;30(3) (Suppl 3):S9-15.

15. Helewa M, Heaman M, Robinson MA, Thompson L. Community-based home-care program for the management of pre-eclampsia: an alternative. Can Med Assoc J 1993;149(6):829-834.

16. Sachan R, Patel ML, Sachan P, Gaurav A, Singh M, Bansal B. Outcomes in hypertensive disorders of pregnancy in the North Indian Population. International Journal of Women's Health 2013;5:101-108.

17. Prakash J, Pandey LK, Singh AK, Kar B. Hypertension in pregnancy: Hospital based study. J Assoc Physicians India 2006;54:273-76.

18. Anjana S, Poonam M, Shradha B. Management of pregnancy induced hypertension. International Journal of Research in Ayurveda \& Pharmacy 2010;1(2):390-398.

19. Suleiman AK. Risk factors on hypertensive disorders among Jordanian pregnant women. Glob J Health Sci 2013;6(2):138-44.

20. Duckitt K, Harrington D. Risk factors for preeclampsia at antenatal booking: systematic review of controlled studies . Brit Med J 2005;12:330(7491):565.

21. Barton JR, O' Brien JM, Bergauer NK, Jacques DL, Sibai BM. Mild gestational hypertension remote from term: Progression and outcome. Am J Obstet Gynecol 2001;184:979-83.

22. Brooten D, Youngblut JM, Brown L, Finkler SA, Neff DF, Madigan E. A randomized trial of nurse specialist home care for women with high risk pregnancies: outcomes and costs. Am J Manag Care 2001;7(8):793-803.

23. Brooten D, Brooks L, Madigan EA, Youngblut JM. Home care of high risk pregnant women by advanced practice nurses: nurse time consumed. Home Healthc Nurse 1998;16(12):823-830.

24. Moodley J. Maternal deaths associated with hypertension in South Africa: lessons to learn from the saving mothers report, 2005-2007. Cardiovas J Afr 2011;22(1):31-5.

25. Malik G. Role of auxiliary nurse midwives in national rural health mission. The Nursing Journal of India 2009:3. Available from www.tnaionline.org/apr09/8.htm[cited 2014Aug 20].

26. Kitzman H, Olds DL, Henderson CR, Hanks C, Cole R, Tatelbaum $\mathrm{R}$ et al. Effect of prenatal and infancy home visitation by nurses on pregnancy outcomes, childhood injuries, and repeated childbearing. A randomized controlled trial. JAMA 1997;278(8):644-52.

27. Feeney IG. Hypertension in pregnancy managed at home by community midwives. Brit Med J 1984;288:1046-47. 


\begin{tabular}{|c|c|c|c|c|}
\hline Demographic Characters & $\begin{array}{c}\text { Home Care (52) } \\
\text { No \% } \\
\end{array}$ & $\begin{array}{c}\text { Conventional Care (51) } \\
\text { No \% } \\
\end{array}$ & $\begin{array}{c}\text { Total (103) } \\
\text { No \% } \\
\end{array}$ & \\
\hline \multicolumn{5}{|c|}{ Age Group (yrs ) } \\
\hline $19-22$ & 1528.8 & 1223.5 & 2726.2 & \multirow{4}{*}{$4.325(0.228)^{*}$} \\
\hline $23-26$ & 1834.6 & 2345.1 & 4139.8 & \\
\hline $27-30$ & 1019.2 & 1325.5 & 2322.4 & \\
\hline $31-34$ & 917.4 & 35.9 & 1211.6 & \\
\hline Mean Age & $25.3 \pm 4.3$ yrs & $24.7 \pm 3.5$ yrs & & $0.829(0.409)^{\$}$ \\
\hline \multicolumn{5}{|c|}{ Education } \\
\hline Primary & & 12.0 & 11.0 & \multirow{5}{*}{$0.6973(0.705)^{*}$} \\
\hline Secondary & 47.7 & 47.8 & 87.8 & \\
\hline High School & 2242.3 & 2243.1 & 4442.7 & \\
\hline Higher Secondary & 917.3 & 1121.6 & 2019.4 & \\
\hline College & 1732.7 & 1325.5 & 3029.1 & \\
\hline \multicolumn{5}{|c|}{ Occupation } \\
\hline Housewife & 4892.3 & 4384.3 & & \multirow[t]{2}{*}{$1.599(0.206)^{*}$} \\
\hline Others & 47.7 & 815.7 & & \\
\hline
\end{tabular}

$* \chi 2$ (p value) \$ t ( $\mathrm{p}$ value)

\begin{tabular}{|c|c|c|c|c|}
\hline & $\begin{array}{c}\text { Home Care (52) } \\
\text { No \% }\end{array}$ & $\begin{array}{c}\text { Conventional Care (51) } \\
\text { No \% }\end{array}$ & $\begin{array}{l}\text { Total } \\
(103) \\
\text { No } \%\end{array}$ & \\
\hline \multicolumn{5}{|c|}{ Parity } \\
\hline Primi & 3159.6 & 2956.9 & 6058.2 & \multirow[b]{2}{*}{$0.080(0.777)^{*}$} \\
\hline Multi & 2140.4 & 2243.1 & 4341.8 & \\
\hline \multicolumn{5}{|c|}{ Gestational Age (weeks) } \\
\hline $20-24$ & 713.5 & 611.7 & 1312.6 & \multirow{3}{*}{$1.29(0.522)^{*}$} \\
\hline $25-29$ & 1834.6 & 1325.5 & 3130.1 & \\
\hline $30-34$ & 2751.9 & 3262.8 & 5957.3 & \\
\hline Mean Weight (kg) & $67.9 \pm 11.9$ & $69.1 \pm 13.9$ & & $0.471(0.638)^{\$}$ \\
\hline Mean SBP (mmHg) & $125.0 \pm 8.0$ & $129.6 \pm 9.8$ & & $2.612(0.010)^{\$}$ \\
\hline Mean DBP(mmHg) & $90.6 \pm 2.4$ & $90.9 \pm 3.6$ & & $0.498(0.619)^{\$}$ \\
\hline
\end{tabular}

${ }^{*} \chi 2$ (p value) ${ }^{\$}$ t (p value) SBP - Systolic blood pressure DBP - Diastolic blood pressure

\begin{tabular}{|c|c|c|c|}
\hline \multirow{2}{*}{ Outcomes } & Baseline & At Delivery & \\
\hline & Mean \pm SD & Mean \pm SD & t test $p$ value \\
\hline \multicolumn{4}{|c|}{ Home Care $(n=52)$} \\
\hline Weight ( Kg ) & $67.9 \pm 11.9$ & $72.9 \pm 12.5$ & 2.0890 .039 \\
\hline SBP ( $\mathrm{mm} \mathrm{Hg})$ & $125.0 \pm 8.0$ & $124.4 \pm 11.6$ & 0.3630 .718 \\
\hline $\mathrm{DBP}(\mathrm{mm} \mathrm{Hg})$ & $90.6 \pm 2.4$ & $86.4 \pm 9.4$ & 3.1100 .003 \\
\hline \multicolumn{4}{|c|}{ Conventional Care $(n=51)$} \\
\hline Weight ( Kg ) & $69.1 \pm 13.9$ & $68.9 \pm 13.7$ & 0.0770 .939 \\
\hline $\mathrm{SBP}(\mathrm{mm} \mathrm{Hg})$ & $129.6 \pm 9.8$ & $131.9 \pm 13.9$ & 1.1930 .238 \\
\hline $\mathrm{DBP}(\mathrm{mm} \mathrm{Hg})$ & $90.9+3.6$ & $87.3+9.8$ & 2.6110 .012 \\
\hline \multicolumn{4}{|c|}{ Table 3: Maternal Outcomes among the Study Participants } \\
\hline
\end{tabular}

SBP - Systolic blood pressure DBP - Diastolic blood pressure 


\begin{tabular}{|c|c|c|c|}
\hline & $\begin{array}{c}\text { Home Care } \\
(n=52) \\
\text { No } \% \\
\end{array}$ & $\begin{array}{c}\text { Conventional Care } \\
(n=51) \\
\text { No } \% \\
\end{array}$ & $\chi^{2} p$ value \\
\hline \multicolumn{4}{|c|}{ Blood Pressure at Delivery } \\
\hline Antenatal women who become normotensive & 2446.2 & 1937.3 & \multirow[b]{2}{*}{0.8380 .3598} \\
\hline Antenatal women who continued to have hypertension & 2853.8 & 3262.7 & \\
\hline \multicolumn{4}{|c|}{ Maternal Morbidity } \\
\hline Pre-eclampsia & 917.3 & 1121.6 & \\
\hline Oligohydromnios & 35.7 & 11.9 & \\
\hline PROM & 11.9 & 35.8 & \\
\hline Sepsis & 23.8 & 47.8 & \\
\hline BP Medications & 1325.0 & 1631.3 & \\
\hline Anemia & 23.8 & 611.7 & \\
\hline \multicolumn{4}{|c|}{ Table 4: Blood Pressure at Delivery and Morbidity Status of Mothers } \\
\hline
\end{tabular}

\begin{tabular}{|c|c|c|c|}
\hline & $\begin{array}{c}\text { Home Care } \\
(n=52) \\
\text { No } \%\end{array}$ & $\begin{array}{c}\text { Conventional Care } \\
\left(\begin{array}{c}n=51) \\
\text { No } \%\end{array}\right.\end{array}$ & \\
\hline \multicolumn{4}{|c|}{ GA ( weeks) } \\
\hline Preterm $\leq 36$ & 47.7 & 611.6 & \multirow{3}{*}{$0.491(0.782)^{*}$} \\
\hline Term $37-40$ & 4688.5 & 4384.3 & \\
\hline Post term $>40$ & 23.8 & 23.9 & \\
\hline Mean GA \pm SD & $38.5 \pm 1.6$ & $38.3 \pm 1.8$ & $0.504(0.616)^{\$}$ \\
\hline \multicolumn{4}{|c|}{ Mode of Delivery } \\
\hline Normal & 2955.7 & 2650.9 & \multirow{2}{*}{$0.237(0.626)^{*}$} \\
\hline Caesarian & 2344.3 & 2549.1 & \\
\hline \multicolumn{4}{|c|}{ Birth Weight } \\
\hline$<2.5 \mathrm{Kg}$ & 59.6 & 815.4 & \multirow[b]{2}{*}{$0.791(0.373) *$} \\
\hline$\geq 2.5 \mathrm{Kg}$ & 4790.4 & 4484.6 & \\
\hline Mean \pm SD ( kg) & $2.97 \pm 0.45$ & $2.96 \pm 0.59$ & $0.072(0.942)^{\$}$ \\
\hline Range (kg) & $1.47-4.20$ & 1.3- 4.09 & \\
\hline \multicolumn{4}{|c|}{ APGAR } \\
\hline $0-3$ & 11.9 & 12.1 & \multirow{3}{*}{$0.751(0.427)^{\$}$} \\
\hline $4-6$ & 11.9 & 35.8 & \\
\hline $7-10$ & 4996.2 & 4792.1 & \\
\hline \multicolumn{4}{|c|}{ Neonatal Morbidity } \\
\hline Birth Asphyxia & 815.6 & 1019.6 & \multirow{4}{*}{$0.728(0.196)^{*}$} \\
\hline Infection / Sepsis & 47.8 & 47.8 & \\
\hline Jaundice & 23.9 & 23.9 & \\
\hline GI Bleed & - & 23.9 & \\
\hline \multicolumn{4}{|c|}{ Table 5: Neonatal Outcomes in the Study Participants } \\
\hline
\end{tabular}

${ }^{*} \chi 2$ (p value) $\$ \mathrm{t}(\mathrm{p}$ value $)$ 